\title{
A Quantitative Analysis of Wind Curtailment Strategy in Multiple Temporal and Spatial Scales
}

\author{
Jia Lin, \\ Power Grid Research Institute \\ North China Electric Power University \\ Beijing, China \\ e-mail: linchia@126.com \\ Dayong $\mathrm{Yu}$ \\ Design Center \\ State Power Economic Research Institute \\ Liaoning, China \\ e-mail: ydy1970@126.com \\ Dongxue Li \\ Design Center \\ State Power Economic Research Institute \\ Liaoning, China \\ e-mail: ldxztg79@163.com
}

\author{
Qiang Ma \\ Design Center \\ State Power Economic Research Institute \\ Liaoning, China \\ e-mail: maqiang_716@163.com \\ Tong Jiang \\ Power Grid Research Institute \\ North China Electric Power University \\ Beijing, China \\ e-mail: jiangtong@ncepu.edu.cn
}

\begin{abstract}
In order to solve the actual needs of developing strategies to improve the capacity of wind power consumption, this paper analyses the factors affecting the capacity of wind power consumption in multiple temporal and spatial scales, as well as measures to improve regional wind power consumption capacity. The calculation model for the contribution of wind curtailment factors is proposed, quantitative modelling the contribution of various factors. By the contrast of contribution, operators could visually assess the extent of the impact factors, which allow them to set up coping strategies according to the severity level of issues.
\end{abstract}

Keywords-wind curtailment strategy; quantitative analysis; contribution; mutiple temporal and spacial scales

\section{INTRODUCTION}

The wind curtailment problem is common in "Three Northern Regions" in China, bothering both the government and grid operators. It's technically difficult to split the impact of certain factors, because that wind curtailment is a comprehensive problem containing several correlative issues. Recently, most scholars have studied certain issue independently, such as the impact of transmission mode $[1,2]$. However, study that considers and compares the various factors from the perspective of the whole network is needed.

This paper analyses the factors affecting the capacity of wind power consumption in the multiple temporal and spatial scales, quantitatively models the contribution of various factors, and allows operators to set up coping strategies according to the severity level of issues.

\section{A WIND CURTAILMENT FACTOR SYSTEM IN MULTIPLE TEMPORAL AND SPATIAL SCALES}

Follow the logic of wind power electricity generation, transmission and distribution, the factors affecting the capacity of wind power consumption are divided into several issues, as Table. 1: wind resource issue, wind power prediction accuracy issue, wind turbine running performance issue, reactive compensation issue, transmission capacity issue, electricity energy formation issue, load characteristics issue and imbalance issue of supply and demand. Certain factor is related to several evaluation indexes. The factors affecting the capacity of wind power consumption will be presented in multiple temporal and spatial scales [3], as Fig. 1, to discriminate the impact scope and scale of different factors.

\section{A. Wind resource issue}

The impact of wind resource issue is mainly reflected in the average wind power density and available wind power density [4]. When the wind power density varies within the available range of the normal operation, wind turbines work and produce electricity. This condition is settled by nature, which should be serious considered before a wind farm is built.

\section{B. Wind power prediction accuracy issue}

Wind power prediction is included in the basis of the monthly wind power balance and dispatching management. 
Currently, the prediction accuracy varies; long-term wind power prediction has not carried out well. Both limit the ability of wind power integration [5]. When strategy of improving wind power prediction accuracy is proposed, the extent is limited to $100 \%$ and the cost will increase dramatically.

TABLE I. WIND CURTAILMENT FACTOR SYSTEM

\begin{tabular}{|c|c|c|c|}
\hline $\begin{array}{l}\text { Issues } \\
\text { No. }\end{array}$ & Issues & $\begin{array}{l}\text { Index } \\
\text { No. }\end{array}$ & Evaluation Indexes \\
\hline A & $\begin{array}{l}\text { Wind Resource } \\
\text { Issue }\end{array}$ & 1 & $\begin{array}{l}\text { Average Wind Power } \\
\text { Density }\end{array}$ \\
\hline B & $\begin{array}{l}\text { Wind Power } \\
\text { Prediction } \\
\text { Accuracy Issue }\end{array}$ & 2 & $\begin{array}{l}\text { the Prediction Accuracy of } \\
\text { Wind Power }\end{array}$ \\
\hline C & $\begin{array}{l}\text { Wind Turbine } \\
\text { Running } \\
\text { Performance } \\
\text { Issue }\end{array}$ & 3 & $\begin{array}{l}\text { Rate of Wind Turbine } \\
\text { Output }\end{array}$ \\
\hline $\mathrm{D}$ & $\begin{array}{l}\text { Reactive } \\
\text { Compensation } \\
\text { Issue }\end{array}$ & 4 & $\begin{array}{l}\text { the Voltage Stability of } \\
\text { Parallel Point }\end{array}$ \\
\hline $\mathrm{E}$ & $\begin{array}{l}\text { Transmission } \\
\text { Capacity Issue }\end{array}$ & 5 & $\begin{array}{l}\text { Transmission Power of } \\
\text { Tie-line }\end{array}$ \\
\hline \multirow{4}{*}{$F$} & \multirow{4}{*}{$\begin{array}{l}\text { Electricity } \\
\text { Energy } \\
\text { Formation Issue }\end{array}$} & 6 & Thermal Unit Penetration \\
\hline & & 7 & Heating Unit Penetration \\
\hline & & 8 & Wind Power Penetration \\
\hline & & 9 & Spinning Reserve Capacity \\
\hline \multirow{2}{*}{$\mathrm{G}$} & \multirow{2}{*}{$\begin{array}{l}\text { Load } \\
\text { Characteristics } \\
\text { Issue }\end{array}$} & 10 & $\begin{array}{l}\text { the Load Peak and Off-peak } \\
\text { Difference }\end{array}$ \\
\hline & & 11 & $\begin{array}{l}\text { Net Peak Valley Load } \\
\text { Difference }\end{array}$ \\
\hline $\mathrm{H}$ & $\begin{array}{l}\text { Imbalance Issue } \\
\text { of Supply and } \\
\text { Demand }\end{array}$ & 12 & $\begin{array}{l}\text { the Ratio of Wind Power } \\
\text { Installed Capacity to } \\
\text { Maximum Load }\end{array}$ \\
\hline
\end{tabular}

\section{Wind turbine running performance issue}

There are requirements that wind turbine must have low voltage ride through (LVRT) capability to ensure safety and stability. In addition, some can adjust the blade angle to smooth the wind power output. The rate of change of wind power output can be calculated as follows [3], as in

$$
\rho \%=\frac{P(t+T)-P(t)}{P_{\text {base }}} \times 100 \%
$$

$\rho \%$ is used to reflect the fluctuations of power output, which tells the running performance in a way.

$t$ is the moment of calculation.

$T$ represents time interval.

$P(t)$ represents wind power output on moment $t$.

$P(t+T)$ is wind power output on moment $(t+T)$.

$P_{\text {base }}$ refers to the rated power of wind power generator or wind farm.

\section{Reactive compensation issue}

High-power electronic equipment integrated brings up new demands for reactive compensation. The lack of reactive power compensation leads to abnormal voltage level, limiting the ability to accept wind power [6]. Accordingly, the solution to this issue is deploying proper reactive power compensator.

\section{E. Transmission capacity issue}

Wind farms are generally located in remote areas far from load centres, depending on transmission lines to send out electricity. Strategy of investing in new transmission line is limited by cost-benefit analysis [7]. Planning new loads such as desalinator $[8,9,10]$ and data center makes it possible to use wind power locally.

\section{F. Electricity energy formation issue}

The proportion of wind power, thermal power and hydropower, to a certain extent, shows the regulation ability. According to operation data of power grid in the northeast of China, during winter heating period, the heating units accounts for about $50 \%$ of total thermal power, which greatly weakened the peaking capacity of grid. Further, in order to secure stable operation of the power system, wind power penetration does not exceeds $20 \%$ generally [11].

\section{G. Load Characteristics issue}

The characteristics of load varies in different seasons of the same year. The smaller the difference between peak and valley load, the more capable of wind power consumption [12].

\section{H. Imbalance issue of supply and demand}

In parts of the region, the amount of wind power capacity exceeds the maximum power load. Therefore, considering the supply and demand balance of the power system is an important part of the analysis of wind power consumption ability.

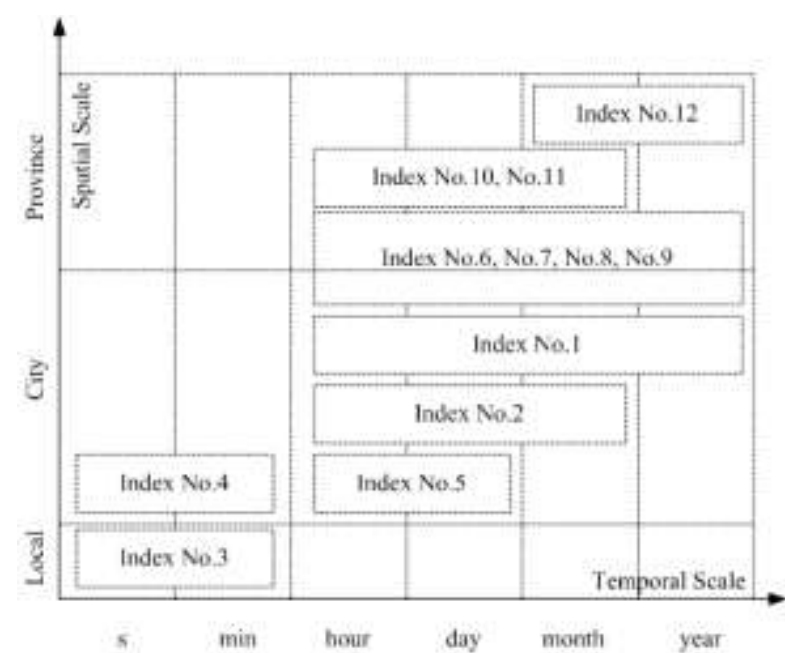

Figure 1. A wind curtailment factor system in multiple temporal and spatial scales

\section{THE CALCULATION MODEL FOR THE CONTRIBUTION OF WIND CURTAILMENT FACTORS}

After analyzing the factors in multiple temporal and spatial scales, the calculation model for the contribution of wind curtailment factors is established to quantify the 
contribution of various factors to wind curtailment problem, which can be applied in problem diagnosis and strategy development. The model can be shown as in

$$
C_{i}=f_{i} \times \frac{R_{i}-S_{i}}{S_{i}} \times 100 \%
$$

$C_{i}$ represents the contribution of i-factor.

$f_{i}$ is impact factor, which means the increment of wind curtailment $(10000 \mathrm{kWh})$ under unit increment of i-factor's evaluation index, obtained by historical data or simulating calculation.

$R_{i}$ is the real value of i-factor's evaluation index, which can be obtained from operating database.

$S_{i}$ is the standard value of i-factor's evaluation index setting by historical data.

Meanwhile, statistical methods based on historical data are the most direct and authentic analyzing methods of wind power law [3]. Commonly, it is proposed to set $S_{i}$ equal to the rated value, such as rated power and rated voltage. When it comes to the prediction accuracy of wind power, $\mathrm{S}_{\mathrm{i}}$ should be set according to guide rule, such as $80 \%$ in local grid.

If several evaluation indexes are considering in one issue and the number of indexes is $N$, the contribution of $i-$ issue can be calculated as in

$$
\left\{\begin{array}{l}
C_{i-i s s u e}=\sum_{j=1}^{N} a_{j} C_{j} \\
\sum_{j=1}^{N} a_{j}=1
\end{array} .\right.
$$

$a_{j}$ is impact factor, which means the increment of wind curtailment $(10000 \mathrm{kWh})$ under unit increment of $\mathrm{j}$-index, obtained by historical data or simulating calculation.

Finally, calculate the contribution of various factors and issues, which affect the capacity of wind power consumption, in order to normalize and compare the severity level of different issues.

\section{EXAMPLES}

Taking a grid in "Three Northern Regions" in China as an analysis example.

According to statistic data of sample power grid, the amount of wind power consumption reached the maximum on November (during heating period), while wind resource utilization dropped. The average of wind power penetration is $20 \%$. Wind power generation throughout the year is approximately $500 \mathrm{GWh}$ and the average wind resource utilization of wind power generation is roughly $77 \%$. To discuss the factors contributing to wind curtailment during heating period, the sample grid is analyzed under the conditions that the spatial scale is city and the temporal scale is month.

Take "Wind Power Prediction Accuracy Issue" or instance. Referring to the experiment done by [13], shown as Table. 2, the decrement of wind curtailment under unit increment of wind power prediction accuracy is 576 $(10000 \mathrm{kWh})$. Therefore the impact factor $\mathrm{f}_{\mathrm{i}}$ of the prediction accuracy is -576 . The real operation data is $85 \%$, while standard value $\mathrm{S}_{\mathrm{i}}$ is $80 \%$ according to guide rule. Then, use (2) to obtain $\mathrm{C}_{\mathrm{i}}$ of wind power prediction accuracy issue.

TABLE II. EXAMPLE OF A GRID IN “THREE NORTHERN REGIONS”

\begin{tabular}{|l|l|l|}
\hline Evaluation Indexes & $\begin{array}{l}\text { Impact } \\
\text { Factor(fi) }\end{array}$ & Standard Value (Si) \\
\hline $\begin{array}{l}\text { The prediction accuracy } \\
\text { of wind power }\end{array}$ & $-576^{*}$ & $80(\%)$ \\
\hline Thermal unit penetration & 6739.2 & $80(\%)$ \\
\hline $\begin{array}{l}\text { Transmission power of } \\
\text { tie-line }\end{array}$ & $-691.2 *$ & $1750($ MVA $)$ \\
\hline $\begin{array}{l}\text { The load peak and off- } \\
\text { peak difference }\end{array}$ & 748.8 & $400(10,000 \mathrm{kWh})$ \\
\hline
\end{tabular}

(fi is negative when the decrease of index leads to the increase of wind curtailment amount)

According to wind curtailment factor system, the contribution of issues can be presented as Table. 3 and Fig. 2.

TABLE III. THE CONTRIBUTION OF ISSUES FOR EXAMPLE GRID

\begin{tabular}{|l|l|}
\hline Issues & Contribution(Ci) \\
\hline Wind Power Prediction Accuracy Issue & -36.0 \\
\hline Electricity Energy Formation Issue & 834.0 \\
\hline Transmission Capacity Issue & 79.0 \\
\hline Load Characteristics Issue & 262.1 \\
\hline
\end{tabular}

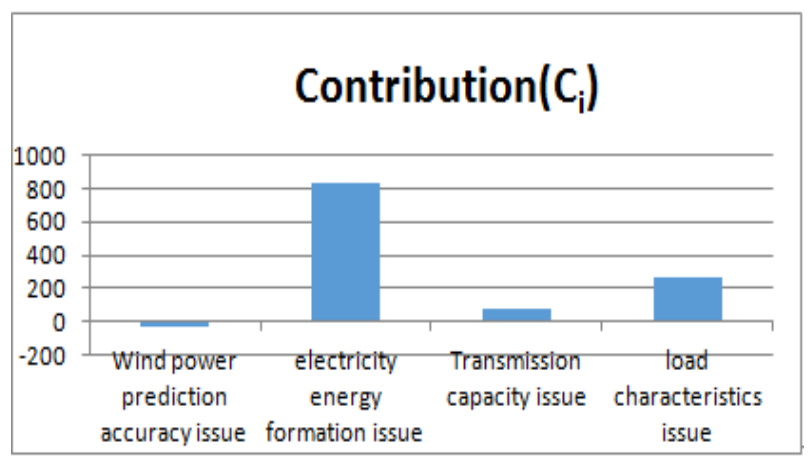

Figure 2. A wind curtailment factor system in multiple temporal and spatial scales

The result indicates that the problem of electricity energy formation issue is more serious than other issues. The contribution value of electricity energy formation issue is 834 , which means that, compared to the standard thermal unit penetration (80\%), the amount of thermal power generation takes a larger slice of electricity supply. And unit decrement of thermal unit penetration (1\%) can increase $834.0(10,000 \mathrm{kWh})$ of wind power consumption. Meanwhile, the prediction accuracy is preciser than standard value, which, by contrast, brings extra 36.0 
$(10,000 \mathrm{kWh})$ of wind power consumption. It is recommended that grid operators should put more emphasis on optimizing electricity energy formation. Relative strategies include decreasing the thermal unit penetration, decreasing the heating unit penetration, increasing the spinning reserve capacity and deploying storage devices.

\section{CONCLUSION}

A wind curtailment factor system in multiple temporal and spatial scales is proposed and the contribution of wind curtailment factors is quantified by calculation model. The example shows the visualization and normalization of this analysis method, which can be applied in problem diagnosis and strategy development.

Furthermore, there are several conditions that should be noted:

1) The cost and benefit of certain strategy could be discussed to assess the economic efficiency.

2) The variation range of indexes mentioned in calculation model should be considered.

3) Based on this research, the optimize combination of several strategies should be discussed.

\section{REFERENCES}

[1] Zhou X, Yi J, Song R, et al. An overview of power transmission systems in China[J]. Energy, 2010, 35(11): $4302-4312$.

[2] Luo G, Zhi F, Zhang X. Inconsistencies between China's wind power development and grid planning: An institutional perspective[J]. Renewable Energy, 2012, 48: $52-56$.

[3] Li J, Qiao Y, Lu Z,Li J. An evaluation index system for wind power statistical characteristics in multiple spatial and temporal scales and its application, Proceedings of the CSEE, 2013, 33(13): 53-61,.

[4] Zhenbin Y, Ruizhao Z, Heng X. Two new concepts on wind energy assessment in wind farm-equivalent wind speed, available wind power density[J]. Acta Energiae Solaris Sinica, 2007, 28(3): 251.

[5] Jia W, Kang C, Li D, et al. Evaluation on capability of wind power accommodation based on its day-ahead forecasting[J]. Power System Technology, 2012, 8: 013.

[6] Yang X, Lin Y. Mechanism of wind power impacting the voltage of power grid[J]. Southern Power System Technology, 2012, 4: 009.

[7] Mount T, Lamadrid A, Maneevitjit S, et al. "Evaluating the net benefits of investing in new wind and transmission capacity on a network," HICSS'09. 42nd Hawaii International Conference on. IEEE, 2009: 1-10.

[8] Zhang Wei, Wu Yaoyong, Distribution scheme for off-grid wind power and sea water desalination united technologies, China Electric Power Construction, 2014, 35(5): 79-83,

[9] Brahma S M, Girgis A A. Development of adaptive protection scheme for distribution systems with high penetration of distributed generation[J]. Power Delivery, IEEE Transactions on, 2004, 19(1): 56-63.

[10] Li M, Liu G, Sun X. Linked distribution of large-Scale offgrid wind power and seawater desalination and hydrogen production industrial bases in China [J]. Resources Science, 2008, 11: 004.

[11] Jiang Shupeng, Qiao Ying, Xu Fei, et al. Capacity optimization and sensitivity analysis of cogeneration system of wind power and energy storage, Automation of Electric Power System, 2013, 37(20): 16-21.

[12] Holmes J D. Effective static load distributions in wind engineering $[\mathrm{J}]$. Journal of Wind Engineering and Industrial Aerodynamics, 2002, 90(2): 91-109.

[13] Liu D, Huang Y, Wang W, et al. Analysis on provincial system available capability of accommodating wind power considering peak load dispatch and transmission constraints[J]. Dianli Xitong Zidonghua(Automation of Electric Power Systems), 2011, 35(22): 77-81. 